\section{Update on perioperative management of the child with asthma}

\author{
Francesco Dones, Grazia Foresta, \\ Vincenzo Russotto
}

Department of Anesthesia and Intensive Care AOUP, University of Palermo, Italy

\section{Abstract}

Asthma represents the leading cause of morbidity from a chronic disease among children. Dealing with this disease during the perioperative period of pediatric surgical procedures is, therefore, quite common for the anesthesiologist and other professionalities involved. Preoperative assessment has a key role in detecting children at increased risk of perioperative respiratory complications. For children without an optimal control of symptoms or with a recent respiratory tract infection elective surgery should be postponed, if possible, after the optimization of therapy. According to clinical setting, loco-regional anesthesia represents the desirable option since it allows to avoid airway instrumentation. Airway management goals are preventing the increase of airflow resistance during general anesthesia along with avoiding triggers of bronchospasm. When their use is possible, face mask ventilation and laringeal mask are considered more reliable than tracheal intubation for children with asthma. Sevoflurane is the most commonly used anesthetic for induction and manteinance. Salbutamol seems to be useful in preventing airflow resistance rise after endotracheal intubation. Mechanical ventilation should be tailored according to pathophysiology of asthma: an adequate expiratory time should be setted in order to avoid a positive end-expiratory pressure due to expiratory airflow obstruction. Pain should be prevented and promptly controlled with a loco-regional anesthesia technique when it is possible. Potential allergic reactions to drugs or latex should always be considered during the whole perioperative period. Creating a serene atmosphere should be adopted as an important component of interventions in order to guarantee the best care to the asthmatic child.

\section{Introduction}

Asthma is one of the most common chronic disease, affecting 300 million people worldwide, with an increasing prevalence especially among children. ${ }^{1}$ In childhood it represents the leading cause of morbidity from a chronic disease.

Several host and environmental factors influencing the development of asthma have been identified. Sensitization to aeroallergens, maternal diet during pregnancy and/or lactation, tobacco smoke, infections and psychosocial elements are the main environmental factors identified. However no intervention has yet been proven to prevent the onset of asthma or to modify its long-term natural course. ${ }^{2}$

Asthma is a chronic inflammatory disorder of the airway characterized by airway hyperresponsiveness associated with recurrent episodes of wheezing, breathlessness, chest tightness and coughing. The widespread but variable airflow obstruction is often reversible either spontaneously or with treatment. ${ }^{1}$ In younger children, however, symptoms could be less specific. ${ }^{2}$

The improvements of medical care have decreased morbidity and mortality and the incidence of perioperative severe complications in asthmatic children undergoing anesthesia and surgery. Nevertheless bronchospasm can still represent a lifethreatening complication $^{3}$ and an accurate attention for details is necessary during the whole perioperative care to prevent the most severe adverse events. The goals of the anaesthesiologic management of the patient with asthma are to prevent the potentially catastrophic event of intraoperative bronchospasm 4 and to tailor an anaesthetic plan to the child in order to ensure an adequate airflow, avoiding drugs and techniques associated with a potential risk of increasing pulmonary resistance.

The aim of this review is to focus on the most debated topics of the anesthesiologic management of the child with asthma trying to clarify the latest observations.

\section{Pathophysiology and clinical considerations}

Airway inflammation is the key feature of asthma. It characterizes patients of all ages and it is permanent even if symptoms are episodic. ${ }^{1}$ The correlation between inflammation and airway hyperresponsiveness has been established, but the mechanisms involved are not completely clear. Airway hyperresponsiveness contributes to airway narrowing and airflow obstruction through several (incompletely understood) mechanisms like changes in smooth muscle contractility or sensory nerve and autonomic activity. 5,6

Several triggers of airway obstruction and symptoms have been identified in childhood: infections, cold air, outdoor air pollution, laughing, crying, activity. ${ }^{2}$

Inflammatory edema and mucous plugging
Correspondence: Francesco Dones, Department of Anesthesia and Intensive Care AOUP, University of Palermo, via Trinacria 32, 90144 Palermo, Italy.

Tel. +39.091.513550. E-mail: donesfra@alice.it

Key words: pediatric, asthma, perioperative management.

Conflicts of interest: all authors declare that there are no conflicts of interest.

Received for publication: 7 December 2011.

Revision received: 29 February 2012.

Accepted for publication: 29 February 2012.

This work is licensed under a Creative Commons Attribution NonCommercial 3.0 License (CC BYNC 3.0).

(C) Copyright F. Dones et al., 2012

Licensee PAGEPress, Italy

Pediatric Reports 2012; 4:e19

doi:10.4081/pr.2012.e19

contribute to airway narrowing by luminal obstruction. ${ }^{3}$

Chronic inflammation is associated with complex structural changes of the airway collectively named airway remodeling. These factors progressively impair response to bronchodilator therapy. 7,8

The following diagram $3,5-10$ (Figure 1) underlines the pathophysiology sequence that occurs in the patient with airway obstruction. Some of the events described are the consequence of a chronic disease (e.g. airway remodeling $)^{7,8}$ but a severe airway obstruction and the related cardiac response may represent the expression of an acute perioperative respiratory complication (bronchospasm) ${ }^{3}$ in a patient with asthma (previous known or not). Air trapping due to decreased airflow (especially during expiration) leads to dynamic hyperinflation (with increasing positive endexpiratory pressure, PEEP) and dynamic compliance reduction of the lungs. ${ }^{3,9}$ Accessory muscles recruitment is necessary to ensure a normal tidal volume and to perform an active exhalation in the presence of a severe airflow obstruction: ${ }^{3}$ an increased work of breathing and oxygen consumption is the consequence. ${ }^{9}$ With air trapping and muscle fatigue development, $\mathrm{CO}_{2}$ retention increases and it represents the sign of decompensation and of a need of immediate ventilatory support. The increasing lung volume and PEEP may lead to a decreased venous return to the heart and hence to systemic hypotension and low perfusion..$^{3,9}$ Hypoxic pulmonary vasoconstriction involves hypoinflated areas of the lung and ventilation/perfusion ratio ( $\left.\mathrm{V}^{\prime} / \mathrm{Q}^{\prime}\right)$ mismatch could be balanced at the beginning. However the increased pulmonary vasculature resist- 
ance is responsible of the right ventricular overload and further oxygen consumption. Hypoxaemia represents the end stage of this sequence and it is the result of the increasing $\mathrm{V}^{\prime} / \mathrm{Q}^{\prime}$ mismatch (due, among other factors, to vasodilation run by inflammation). 10

\section{Preoperative assessment and risk factors evaluation}

\section{History}

Uncontrolled baseline bronchial hyperreactivity represents the most important risk factor for perioperative adverse respiratory events in asthmatic patients. ${ }^{11}$ A correct preoperative history can intercept patients with inadequate control of asthma.12 Information can be obtained from child or parents, preferably both.

A history of a recent flare of the disease requiring oral corticosteroids, an increased use of inhaled short-acting $\beta_{2}$-agonists, a recent exacerbation of asthma symptoms, the occurrence of emergency room or hospital visit during the last months suggest a poorly controlled disease.4,11 According to clinical conditions of the child, elective surgery should be cancelled and rescheduled after the optimization of therapy. However anesthesia may be required in children not responding to treatment of severe symptoms of asthma exacerbation or during urgent diagnostic/therapeutic procedures such as bronchoscopy.

The use of systemic corticosteroids for more than 2 weeks within the prior 6 months should also be sought in order to plan a perioperative steroid therapy for the patients at risk for an adrenal crisis. 1,3,13,14 A history of at least two family members having asthma, atopy, or smoking increases the risk for perioperative respiratory adverse events. ${ }^{15}$ A personal history of eczema has been also considered significant in this sense. 15

Information about other possible risks or complicating factors, like recent infections in upper or lower respiratory tract, history of perioperative bronchospasm or previous pulmonary complications during general anesthesia, 12 obesity, or environmental tobacco exposure should be taken in consideration.

Previous allergic reactions should be investigated. ${ }^{16}$ In a prospective survey, latex was the main cause of perioperative anaphylactic reactions in children (76\%). ${ }^{17-19}$ History is the main tool to investigate a latex sensitivity. Children submitted to multiple surgical procedures, such as for spina bifida, especially at a very young age, are at an increased risk of latex sensitization. It could be useful to ask specifically to parents and children whether contact with rubber toys (e.g. ballons) or rubber dam are responsible of lips and tongue swelling, itching, rash or angioedema.19,20 Asking for allergy to some fruits (e.g. avocado, banana, kiwi, chestnut) and vegetables (e.g. tomato, bell pepper, carrot) has been suggested to be helpful to detect an increased risk of latex sensitivity since there is evidence of cross-sensitivity between several shared antigens. ${ }^{19}$

Concerning upper respiratory tract infections, fever, moist cough and green runny nose are important elements to consider during the preoperative evaluation. ${ }^{15}$ The higher incidence of respiratory adverse events in children with a present or recent respiratory tract infection ${ }^{21}$ might be explained by an increased airway sensitivity provoked by the underlying inflammation and its influence on the autonomic nervous system.6,22 This condition persists after resolution of signs and symptoms for a variable period and rescheduling an elective procedure 2-3 weeks after the upper respiratory tract infection, when possible, is considered a safe approach. ${ }^{15}$ However this last decision should be made on a case by case basis, after a risk-benefit ratio assessment including the child's presenting symptoms and the urgency and type of surgery. Frequency of respiratory infections should also be considered, since a child could experience six to eight episodes per year and it may be difficult to predict a symtoms free period for elective surgery. Nevertheless, even before a non elective surgery, the knowledge of a recent or active respi- ratory infection could alert the anesthesiologist to the potential of complication and the anesthetic management could be modified in order to reduce any risk (e.g. avoiding airway instrumentation if possible). ${ }^{22}$

Obese children have a significantly higher prevalence of coexisting conditions, including asthma. 23

Tait et al. ${ }^{24}$ have identified obesity as an independent predictor of perioperative critical adverse events in children. El-Metainy et al. ${ }^{25}$ have observed a significant association between obesity and asthma and a higher occurrence of perioperative bronchospasm in obese children, especially with coexisting asthma. An association between obesity and quality of control was also identified for all ages. ${ }^{1}$ Lung mechanics alterations, pro-inflammatory state and genetic, hormonal or neurogenic factors are some of the proposed mechanisms that could influence the development of asthma and its clinical course in the obese patient.26,27 Environmental tobacco smoke exposure increases the incidence and severity of asthma and respiratory illness. Several studies have demonstrated that environmental tobacco smoke exposure is an independent predictor of adverse respiratory events in children receiving general anesthesia ${ }^{28}$ and of laryngospasm at the emergence from anesthesia, ${ }^{29}$ especially in girls and in children whose mothers had a lower educational level and were exposed to maternal smoke. ${ }^{30}$

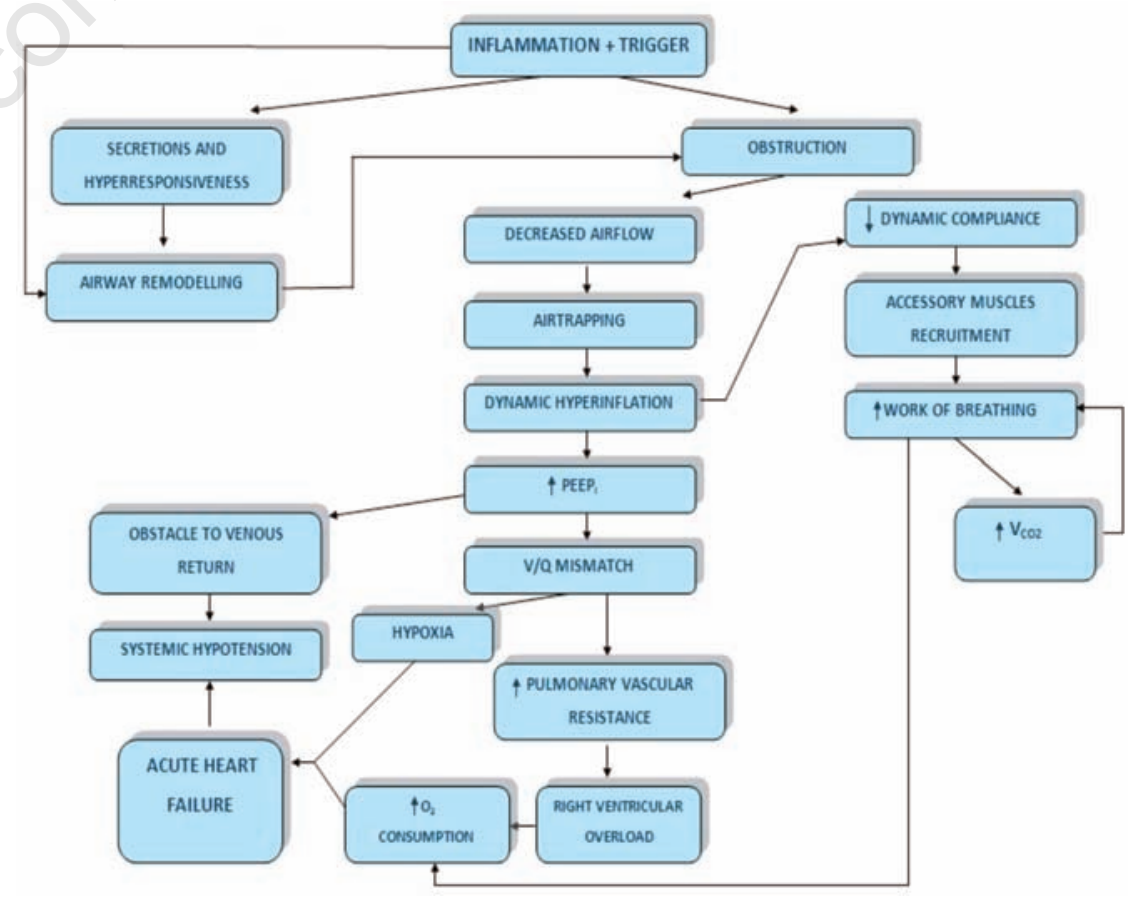

Figure 1. Pathophysiology of airway obstruction. 


\section{Physical examination}

Physical examination is usually negative between exacerbations. ${ }^{3}$ Wheezing should be detected on auscultation and accessory muscles recruitment should be sought. Signs or symtoms of respiratory infections should be detected and decision about suitability for surgery should be made after a complete evaluation of the current clinical condition. ${ }^{15,22}$

\section{Functional tests}

Spirometric evaluation could be important in individuals suffering from severe bronchospasm or with uncertain anamnestic data. ${ }^{11}$ However patient compliance in the pediatric population should be considered and could represent the main limit to the application of functional tests.

Functional tests could be particularly useful to assess bronchodilation response to therapy in children as they could be unaware of significant changes of lung function and symptoms could not be easily adopted to assess potential optimization of respiratory function. ${ }^{31}$

Forced Expiratory Volume in the 1st second (FEV1) has been included as one of the parameters estimating the level of asthma control. A normal FEV1 is associated with a well controlled disease whereas a FEV1 $<80 \%$ of predicted value or of the personal best (if known) express a partly or not controlled disease. ${ }^{1}$ As FEV1 requires a high grade of cooperation of the child to obtain a valid estimation, its feasibility is limited to children above the age of 5 years. ${ }^{31}$ Moreover, though functional tests may improve the evaluation of impairment of respiratory function, they don't quantify perioperative respiratory risks: ${ }^{31}$ younger patients may have a high level of bronchial hyperreactivity without any spirometric parameters abnormalities, implying a potential risk of underestimation. 12

Concerning respiratory function modification during general anesthesia, well controlled asthmatic children exhibit a decrease in FEV1 and Peak Expiratory Flow (PEF); anyway the decrease appears to be similar to the one observed in healthy children. ${ }^{32}$

\section{Lab tests}

Eosinophilic cationic protein (ECP) is a marker of eosinophil activation; ECP measurement was proposed as an index of severity of the disease and of compliance to regular treatment. Scalfaro et al. ${ }^{33}$ have measured ECP levels in serum to find any possible correlation between severity of the disease and respiratory resistance (Rrs) increase after intubation; nevertheless they have not found any correlation between either asthma history or serum ECP level and Rrs response to endotracheal intubation. ${ }^{3}$ Von Ungern-Sternberg et al. 34 have observed a significant correlation between ECP levels in BAL fluids of children undergoing general anesthesia and the degree of airway instability and thus of perioperative bronchospasm. Further investigations are necessary before the feasibility of these observations in the clinical setting.

Systematic preoperative screening for latex allergy is not advisable since a high percentage of population is sensitized to latex antigens (approximately 7-8\%, detected by latex specific IgE). 20,35

Therefore high risk children should be identified through history 19,20 and allergic tests should be performed only in this group of patients. ${ }^{36}$ If the clinical history concerning allergies is positive or equivocal, the patient should be referred to an experienced allergologist to perform preoperative tests. ${ }^{20}$ According to the local availability, either a blood test for specific IgE or skin testing could be performed.20

\section{Intraoperative Management}

\section{Premedication}

Since it is recognized that the psychological component of asthma in the child may influence the clinical course and the recurrence of acute attacks, ${ }^{1,2}$ it is important to guarantee a serene atmosphere and to avoid as much as possible all potential stressful events. According to our experience, allowing the presence of a selected ${ }^{37}$ and prepared parent in the operating room, until the induction of anesthesia, is a simple but important element in order to avoid child anxiety. It represents a component of a novel, multimodal, family-centered approach that should be applied in the perioperative care of the child. 38,39

A premedication with midazolam could be necessary when anxiety (with the consequent hyperventilation) is not well controlled; 40 the choice of the route of administration is one of the key point; rectal and oral administrations appear to be the least invasive ways; inhalational administration may be a valid alternative, but its potentially irritating effects make it a not recommended route in asthmatic patients. The use of oral midazolam $0.5 \mathrm{mg} / \mathrm{kg}$ has been proved safe in the asthmatic child; 41 in our experience the administration of rectal midazolam $0.6 \mathrm{mg} / \mathrm{kg}$ is safe and well tolerated too, especially in younger children.

It is important to continue the usual inhalational therapy until the day of surgery. ${ }^{14}$ The use of inhaled $\beta_{2}$ agonists (salbutamol) prior to the theater is useful to prevent the respiratory resistance increase observed after endotracheal intubation under sevoflurane in midly to moderate asthmatic children. 33

Premedication with corticosteroid or antihistaminic drugs does not guarantee that an anaphylactic reaction will not occur and its extensively use in atopic children appears not to be justified. 16

\section{Induction and mantainance}

\section{Airway}

Airway instrumentation represents a well known trigger of bronchospasm. ${ }^{3}$ The direct mechanical stimulation of airway that occurs during endotracheal intubation could be responsible for a parasympathetic mediated reflex ${ }^{27}$ and for the release of substance $\mathrm{P}$ and neurokinine $\mathrm{A}$ as a consequence of fibers $\mathrm{C}$ stimulation. ${ }^{42} \mathrm{An}$ increased risk for respiratory adverse events in the child has been observed with a failure on airway securing and when more attempts of airway securing were requested. According to these observations, the use of face mask or laryngeal mask in the child with asthma is considered more reliable than tracheal intubation. 15,43 However when bronchospasm (or obviously laryngospasm) occurs, endotracheal intubation seems to be a more reliable method of airway securing according to our experience.

The use of lidocaine in order to prevent bronchospam following airway instrumentation and Rrs increase after tracheal intubation is controversial. Its irritating effect has been supposed to be responsible for the observed bronchospasm after lidocaine inhalation, especially in patients with airway hyperresponsiveness. ${ }^{44}$ Intravenous (IV) lidocaine administration shows a benefit in some but not all studies enrolling anesthetized humans. ${ }^{45-49} \mathrm{~A}$ central nervous system involving mechanism has been proposed to explain the possible IV lidocaine benefit.47 An airway narrowing was observed after IV lidocaine in non anesthetized asthmatic subjects without airway stimulation and it has been supposed that baseline increasing airway tone after IV lidocaine could explain its inconstant beneficial effect after tracheal intubation. ${ }^{47}$ However a case of a severe bronchospasm occurring in an asthmatic child has been recently reported and repeated airway auscultation has been recommended after IV lidocaine use. ${ }^{49}$

When endotracheal intubation is performed, the use of uncuffed endotracheal tubes appears to be the first choice option in children, especially in smaller ones; anatomical features and an appropriate tube size ensure an adequate sealing. ${ }^{50-53}$ The presence of asthma may represents a further indication to uncuffed tube usage. When a cuffed endotracheal tube is required (e.g. head-neck surgery, neurosurgery, laparoscopic surgery) a perfect timing of extubation is essential; indeed cuff deflating could represent a further irritating factor. In order to avoid airway reflexes, extubation could be performed when the child is deep but with a spontaneous and valid respiratory activity.22 However awake extubation is 
necessary for some surgical interventions (e.g. craniofacial surgery), when intubation was difficult, when there is concern for aspiration of gastric content or according to hospital organization. 54

Concerning the use of laryngeal masks, classic pediatric size models are not provided of a drainage tube ${ }^{55}$ and considering also the bigger size of the tongue in proportions to the other anatomical structures, suction of airway and gastric secretions before emergence could not be feasible and bronchospasm triggering by secretions should, therefore, be considered.

Ventilation with face mask should be avoided when it is not possible to establish the complete gastric emptying.

\section{Muscle relaxation}

Among pediatric anesthesiologists, the practice of induction without muscle relaxant use is common. $46,56,57$ According to our experience, intubation is usually performed under deep inhalation anesthesia and muscle relaxation drugs are not necessary during the majority of ambulatory and minor surgical procedures, especially for younger children. Avoidance of these drugs when not necessary reduces the side effects related to their mechanism of action (muscarinic agonism and histamine release), the incidence of allergic reactions and the adverse effects due to reversal drugs using. ${ }^{58}$ However muscle relaxation may be useful for certain surgical procedures to improve operative conditions (e.g. major abdominal operations). For this purpose, the use of vecuronium and cisatracurium is considered safe in the asthmatic patient according to their lower affinity to $\mathrm{M}_{2}$ muscarinic receptors and power of histamine release. 4,59

Mivacurium has been identified as a trigger of bronchospasm in asthmatic children according to its histamine (and maybe other mediators) release capacity in a dose-dependent manner. 60

Atracurium in asthmatic patients should be used with caution in dose and rate of administration.4,61 The use of muscle relaxation reversal drugs should be avoided since they increase airway secretions and bronchial hyperactivity. 58 However complete reversal of neuromuscular blockade should be carefully verified in order to ensure an adequate postoperative ventilation. Sugammadex, a selective neuro-muscle blockers binding agent, could be used for a rapid muscle relaxation reversal, avoiding the side effects of anticholinesterase drugs, ${ }^{62,63}$ but further investigations are necessary before its routinary use in the pediatric and asthmatic population.

\section{Inhalational agents}

Inhalational agents have been the anesthetics of choice for patients with airway hyperresponsiveness. Volatile agents have shown a bronchodilatory effect, and a decrease in histamine release from leukocytes has been observed with their use. ${ }^{4}$

Desflurane is the only inhalational anesthetic not recommended in patients with airway hyperresponsiveness; it has been associated with coughing, laryngospasm, bronchospasm and an increase of secretions. The increase in resistance and inertance in children with airway hyperresponsiveness, more susceptible to the irritative nature of desflurane, appears to involve the peripheral airways too. 64

Sevoflurane is the most used volatile agent for anesthesia in children. Habre et al. ${ }^{65}$ have observed a small but significative increase of Rrs after endotracheal intubation under sevoflurane (1.2 MAC) in asthmatic children; however a decrease in Rrs both in asthmatic and in non asthmatic children has been observed after an increase of sevoflurane concentration (1.7 MAC). Although the increase of Rrs has been not associated with clinically significant respiratory adverse events, caution has been recommended for children with more severe and unstable asthma.

The administration of inhaled $\beta_{2}$-adrenergic agonists before tracheal intubation under sevoflurane appears to prevent the Rrs increase. The same authors 33 have investigated the use of salbutamol in mild to moderate asthmatic children under sevoflurane, observing a protective effect in this group of patients. However the prophylactic effect seems to be incomplete, showing a decrease in the airway resistance component but not in the parenchymal one.

Recently fentanyl has been studied in order to detect a protective effect against respiratory reflexes in children under sevoflurane: Thomas et al .66 have found the same incidence of laryngospasm in children anesthetized with sevoflurane despite the administration of two successive doses of $1.5 \mathrm{mcg} / \mathrm{kg}$ of fentanyl, probably for the lower depressant action of opioids on upper airway originating stimuli compared to lower airway originating ones.

The incidence of laryngospasm seems to be higher using sevoflurane than propofol unless cough and expiratory reflexes have been observed to be lower under sevoflurane anesthesia, regardless of level of hypnosis. ${ }^{67}$

\section{Intravenous agents}

Several studies have been conducted to evaluate the effects of intravenous agents on respiratory resistances. Using an animal model, Brown et al. 68 have observed a dose dependent attenuation of vagal nerve stimulation-induced bronchoconstrinction after the infusion of propofol or ketamine. They supposed a local, neurally mediated, mechanism. The same authors have underlined the importance of the preservative agents contained in some propo- fol formulations (e.g. metabisulfite) in influencing these observations. ${ }^{69}$

In a population of non asthmatic patients, etomidate, propofol and thiopental have been compared for their effect on respiratory resistance after tracheal intubation, observing the lowest Rrs increase after propofol induction. ${ }^{70}$ Recently a neurokinin A involving mechanism has been observed in an animal model investigating the tracheal smooth muscle contration attenuation by propofol.71

There is concern about a higher risk of adverse reactions to propofol in patients with a sensitivity to some food (e.g. eggs, peanuts and soybean oil).72 A possible anaphylaxis after propofol administration in a child with several food allergies (eggs and peanut oil), atopy and reactive airway disease has been reported; the authors suggest to avoid propofol in patients with a documented allergy to these foods whether it is possible. ${ }^{73}$ It is likely that the manufacturing process of propofol removes or denatures the proteins which are responsible for egg and soya allergies. However a cautious approach for these groups of patients has been recently suggested. ${ }^{20}$ Use of propofol, therefore, should be evaluated after a risk-benefit balance in the single child. ${ }^{20,74-76}$

Ketamine has been promoted in the past as the intravenous anesthetic of choice for the patient with asthma. ${ }^{14}$ Its bronchodilator effect is related to the systemic catecholamine increased level following its infusion and to a direct interference with the parasympathetic and endothelin pathways.3,77 The increase of airway secretion represents a disadvantage of its use in the asthmatic child when not associated with an anticholinergic drug. ${ }^{3,4} \mathrm{~A}$ big randomized controlled trial involving asthmatic children is necessary in order to justify its use as a first choice intravenous agent.

Concerning the use of opioid analgesics, histamine-release potential of morphine is well known ${ }^{78}$ and its use in asthmatic patients has been discouraged. Conversely, synthetic opioids like fentanyl and remifentanyl have not been associated with a significant histamine release ${ }^{78}$ and therefore they have been used in asthmatic patients. Despite their off-label condition in pediatrics, their use is widespread and experience with these drugs is growing.

Coughing after fantanyl and remifentanyl intravenous administration has been reported in adults and children ${ }^{79-82}$ and risk seems to be higher in this last group; 83 since coughing could represent a trigger of bronchospasm in asthmatic children, particular attention should be paid during and after their use.

\section{Mechanical ventilation}

Mechanical ventilation should be tailored to the pathophysiologic changes observed in the child with asthma. In order to prevent air trapping due to increased expiratory resistances, a 
longer expiratory time should be assured and thus an adeguate respiratory frequency rate adopted. The aim of this strategy is to avoid intrinsic positive end-expiratory pressure (PEEP) and the subsequent events described above. ${ }^{3,9,84}$

Plateau pressure (Pplat), which is the expression of post-inspiratory alveolar pressure, should be assessed and monitored in order to prevent barotrauma. , $^{9,85-87}$

Inhaled gases should be properly warmed and humidified, ${ }^{3}$ especially when a low flow circuit is not used, since cold and dry air could represent a trigger of bronchospasm. ${ }^{1}$

\section{Perioperative complications}

Complications could be divided (Table 1) into two big groups: complications due to airway management (bronchospasm, laryngospasm, cough, oxygen desaturation, stridor) ${ }^{15}$ and complications due to air trapping (hypotension, pneumothorax, subcutaneous emphysema, cardiac arrest).3,84,85 Even if not specifically related to the pathophysiology of asthma, anaphylaxis could be considered among the possible complications of the child with atopy and allergic asthma. 14,19

The incidence of complications in asthmatic patients appears to be low, according to reported data. Warner et al. ${ }^{88}$ have found a further low incidence of complications in children $(0,6 \%$ of perioperative respiratory complications in patients aged $<9$ vs. $2.4 \%$ in patients aged $>9$; laryingospasm was the only complication observed in patients aged 0-9).

Tube malposition and tube occlusion because of secretions are the first causes of complications and they must be rapidly verified at the occurrence of signs suggesting a possible adverse event. ${ }^{27}$ Intraoperative bronchospam is recognized by polyphonic, bilateral, expiratory wheeze, increased airway pressure, endtidal $\mathrm{CO}_{2}$ rise and possibly hypoxemia.

Table 1. Classification of perioperative complications of the child with asthma.

\begin{tabular}{l} 
Complications related to airway management \\
Bronchospasm \\
Laryngospasm \\
Cough \\
Oxygen desaturation \\
Stridor \\
Complications related to air trapping \\
Hypotension \\
Pneumothorax \\
Subcutaneous emphysema \\
Cardiac arrest \\
\hline Others \\
Anaphylaxis \\
Adrenal crisis \\
\hline
\end{tabular}

In awake child wheezing is associated with prolonged expiration and accessory muscles recruitment with increased respiratory effort. In most severe cases respiratory silence represents the complete airflow arrest. The differential diagnosis, along with mucous plugging and tube malposition (e.g. kinked, bronchial intubation with unilateral wheezing) includes pulmonary edema and tension pneumotorax. The possibility of a foreing body obstruction (e.g. a tooth) should also be considered.3,27 Bronchospasm should be promptly treated since development of hypoxia is responsible for serious and early injuries in children. $100 \%$ oxigen shoud be administered and anesthesia deepened (raising the concentration of inhalational anesthetics). Manual bag ventilation could be useful to asses compliance of the thoraco-pulmonary system and to achieve a rapid inspiratory flow to facilitate a longer expiratory time..$^{3,27} \mathrm{~A}$ rapid-acting $\beta_{2}$ agonist should be administered via a nebulizer (2.5-5 mg every 20-30 min). ${ }^{14}$ Corticosteroid therapy is usually administered even if it does not represent a first line therapy of bronchospam (4 $\mathrm{mg} / \mathrm{Kg}$ hydrocortisone e.v.). ${ }^{14,27,89}$ Magnesium sulfate ev, a drug proposed for status asthmaticus, has been included as a second line treatment for persistent bronchospasm $(40 \mathrm{mg} / \mathrm{Kg}$ over $20 \mathrm{~min}) .3,9,14$ For refractory bronchospasm or when an anaphylactic reaction is suspected, epinephrine use should be promptly considered (1-10 $\mathrm{mcg} / \mathrm{Kg}$, depending on the severity of bronchospasm and patient's response). $19,89,90$

The incidence of perioperative anaphylaxis in children is 1:7,700 and latex represents the main substance involved in this population ( $76 \%$ of reactions). ${ }^{17,18}$ It has been reported that a history of atopy is associated with an up to 10 -fold increase of latex sensivity. ${ }^{19}$ As mentioned above (see History), children at increased risk of latex sensitivity are those who have undergone multiple surgeries (especially in early life, e.g for congenital urologic, gastrointestinal and tracheoesophageal defects) as well as children with spina bifida. 19

Intraoperative allergic reactions have a broad spectrum of manifestations depending on trigger agent, its route and rate of administration, the nature of the patient's hypersensitivity, the state of health of the patient and the effects of concomitant medications (e.g. antihistaminic drugs, $\beta$ blockers). ${ }^{20}$ The clinical features usually develop within few minutes but may be delayed by up to an hour. ${ }^{20}$ Distinction between the allergic nature of a reaction and a non-immunologic adverse event, such a direct non-specific hystamine release, could be impossible on a clinical basis. However clinical manifestations seem to be more severe when they occur during an allergic anaphylaxis. ${ }^{18,20}$ Clinical features of an anaphylactic reaction include hypotension, tachycardia or bradycardia, bronchospasm and hypoxia, cutaneous manifestations such as flushing, erythema, rash or urticaria, angioedema and cardiac arrest. 19,20 In patients with pre-existing asthma, bronchospam could be more common. ${ }^{20}$ Cutaneous manifestations may be more likely observed during non-allergic anaphylaxis or may be masked by surgical drapes during an allergic anaphylaxis. ${ }^{18,19}$ When a single clinical sign represents the presentation of anaphylaxis, it could easily be misdiagnosed since other causes related to anesthesia are commonly sought. Considering anaphylaxis as the cause of an intraoperative adverse event such as hypotension or bronchospam, unless there exists a more likely cause, could represent an advisable approach, especially in high risk patients. ${ }^{19,20,89}$

When a trigger substance is suspected it should be promptly removed. ${ }^{19,89}$ Cardiovascular instability could be treated with intravenous boluses of balanced salt solution (20 $\mathrm{mL} / \mathrm{Kg}$ during 10-20 min) and Trendelenburg position. ${ }^{19}$ Balanced salt solutions containing sodium metabisulfite as stabilizer should be avoided since thay could provoke bronchospam in asthmatic patients. ${ }^{91}$ According to the severity of bronchospasm and hypotension, intravenous epinephrine should be associated to fluid resuscitation (from 1-10 $\mathrm{mcg} / \mathrm{Kg}) .{ }^{19}$ After stabilization of clinical condition, the allergic nature of the reaction should be confirmed along with the responsibility of the suspected agent in order to provide precise recommendations for future anesthetic procedures. A detailed description of the reaction, its time of onset and its relation with drugs administration and other events should be provided by the anesthesiologist to the specialist centre to which the patient should be referred. Blood samples should be taken as soon as possible after the stabilization of the clinical condition, 1-2 hours after the onset of the event and at $24 \mathrm{~h}$ or during convalescence: these samples are useful for mast cell tryptase level determination, a commonly used marker of mast cell degranulation. Skin tests for the suspected agent and specific IgE determination, according to local availability, are the other tests which should be performed in the allergology centre. . $^{19} 20$

Suppression of hypothalamic-pituitaryadrenal axis may be present after a steroid therapy and thus an adrenal crisis may be precipitated by the surgical stress. ${ }^{14}$ Such possibility should be considered particularly in children requiring high doses of systemic corticosteroids to control asthma, but also in children using high doses of inhaled corticosteroids. ${ }^{92,93}$ Intravenous hydrocortisone and fluid resuscitation are the key point of therapy for the adrenal crisis, along with treatment of hypoglicemia. 14 


\section{Postoperative Care}

The control of post-operative pain has a key role in the post-operative management of the child; 94 furthermore in the asthmatic child uncontrolled pain could induce a stressful state and provoke bronchospasm and other complications. Pain should be prevented or rapidly controlled; 94 the use of non-pharmacological strategies may have positive effects and contribute to create a relaxing environment around the child and his family. 38

A local/regional anesthesia technique should be always chosen unless there are important contraindications not to. ${ }^{94}$ When a systemic analgesia is required, acetaminophen (paracetamol) is the first choice drug to treat mild to moderate post-operative pain in children. ${ }^{95}$ Acetaminophen has been associated to bronchospasm and wheezing, especially in patients with aspirin-sensitivity history; 1,96 glutathione depletion in the respiratory tract or trigger action of some additives have been suggested as possible mechanisms. ${ }^{96,97}$ However the association between reported reactions to paracetamol and a real hypersensitivity to this drug appears to be weak in most cases, and thus paracetamol remains a valid alternative to non-steroid anti-inflammatory drugs (NSAIDs) in asthmatic patients. ${ }^{96,98}$ Anyway many asthmatic children can take NSAIDs without reactions; it could be useful to check any past exposure and reactions to NSAIDs.1,94 Because of the association between aspirin and Reye syndrome, aspirin is today rarely administered to children and aspirin sensitivity could be not recognized in young children with asthma. Aspirin-induced asthma is probably underestimate in children;97 aspirin hypersensitivity seems to be present in about $2 \%$ of children, ${ }^{94}$ but this percentage increases when children undergo an oral provocation test.

It has been suggested that NSAIDs like ibuprofen could offer a protective effect when used in acute scenarios (e.g. post-operative pain) because of the antinflammatory activity on the airway inflammation, known as one of the main features of pathogenesis of asthma. ${ }^{97}$

Despite diclofenac has been proven safe in children with asthma in some studies, authors of a recently published Cochrane review have concluded that further investigation are required to definitely asses its optimal dosing and safety. 99

\section{Conclusions}

Asthma is a very common disease, with increasing trends especially in children ${ }^{2}$ and all professionalities involved in the pediatric setting have to handle with it.

The correct evaluation of the baseline disease is the key point of preoperative assessment; $1,4,11$ every possible risk factor for respiratory complications must be taken into consideration, 15 corrected if possible or suggest to reschedule surgery if elective and whether this is feasible based on clinical conditions of the child. According to the clinical setting, locoregional anesthesia should be always considered as the fist choice for the child with asthma. ${ }^{14}$

Airway should be carefully managed and inhalational anesthesia appears to be the best option in the asthmatic child under general anesthesia. Perioperative complications should be promptly recognized and treated. 19,88-93 An adequate post-operative pain control may reduce the risk of complications and improve the outcome of the patient. ${ }^{94}$ A proper perioperative management of the child with asthma has a key role for an uneventful anesthesia with a sufficiently low risk of serious complications.

\section{References}

1. Global Initiative for Asthma (GINA). Global strategy for asthma management and prevention, updated 2010. Available from: http://www.ginasthma.org/search.html?q= Global+strategy+for+asthma+management+and+prevention

2. Global Initiative for Asthma (GINA). Global strategy for the diagnosis and management of asthma in children 5 years and younger, 2009. Available from: http://www.ginasthma.org/guidelines-global-strategy-for-the-diagnosis.html

3. Woods BD, Sladen RN. Perioperative considerations for the patient with asthma and bronchospasm. Br J Anaesth 2009;103: 57-65.

4. Burburan SM, Xisto DG, Rocco PRM. Anaesthetic management in asthma. Minerva Anesthesiol 2007;73:357-65.

5. Busse WW. The relationship of airway hyperresponsiveness and airway inflammation: airway hyperresponsiveness in asthma: its measurement and clinical significance. Chest 2010;138:4-10.

6. Cockcroft DW, Davis BE. Mechanisms of airway hyperresponsiveness. J Allergy Clin Immunol 2006;118:551-9.

7. Homer RJ, Elias JA. Airway remodeling in asthma: therapeutic implications of mechanisms. Physiology 2005;20:28-35.

8. Vignola AM, Mirabella F, Costanzo G, et al. Airway remodeling in asthma. Chest 2003;123:417-22.

9. Werner HA. Status asthmaticus in children. A review. Chest 2001;119;1913-29.

10. Harris RS, Winkler T, Tgavalekos N, et al.
Regional pulmonary perfusion, inflation, and ventilation defects in bronchoconstricted patients with asthma. Am J Respir Crit Care Med 2006;174:245-53.

11. Liccardi G, Salzillo A, De Blasio F, et al. Control of asthma for reducing the risk of bronchospasm in asthmatics undergoing general anesthesia and/or intravascular administration of radiographic contrast media. Curr Med Res Opin 2009;25:162130.

12. Liccardi G, Salzillo A, Piccolo A, et al. The risk of bronchospasm in asthmatics undergoing general anesthesia and/or intravascular administration of radiographic contrast media. Physiopatology and clinical/ functional evaluation. Eur Ann Allergy Clin Immunol 2010;43:167-173.

13. National Heart, Lung, and Blood Institute, National Asthma Education and Prevention Program. Expert Panel Report 3: Guidelines for the diagnosis and management of asthma. Full report 2007. Bethesda, MD: U.S. Department of Health and Human Services, National Institutes of Health; 2007. NIH Publication No. 074051 Available at: http://www.nhlbi.nih.gov /guidelines/asthma/asthgdln.pdf.

14. Doherty GM, Chisakuta A, Crean P, et al. Anesthesia and the child with asthma. Paed Anaesth 2005;15:446-54.

15. Von Ungern-Sternberg BS, Boda K, Chambers NA, et al. Risk assessment for respiratory complications in paediatric anaesthesia: a prospective cohort study. Lancet 2010;376:773-83.

16. Mertes PM, Laxenaire MC, Lienhart A. et al. Reducing the risk of anaphylaxis during anaesthesia: guidelines for clinical practice. J Invest Allergol Clin Immunol 2005; 15:91-101.

17. Murat I. Anaphylactic reactions during paediatric anaesthesia; results of the survey of the French Society of Paediatric Anaesthetists (ADARPEF) 1991-1992. Paed Anaesth 1993;3:339-43.

18. Mertes PM, Laxenaire MC, Alla F. Anaphylactic and anaphylactoid reactions occurring during anesthesia in France in 1999-2000. Anesthesiology 2003;99:536-45.

19. Sampathi V, Lerman J. Case scenario. Perioperative latex allergy in children. Anesthesiology 2011;114:673-80.

20. Harper NJN, Dixon T, Dugué P, et al. Suspected anaphylactic reactions associated with anaesthesia. Anaesthesia 2009;64:199-211.

21. Tait AR, Malviya S,Voepel-Lewis T, et al. Risk factors for perioperative adverse respiratory events in children with upper respiratory tract infections. Anesthesiology 2001;95:299-306.

22. Tait AR, Malviya S. Anesthesia for the child with an upper respiratory tract infection: 
still a dilemma? Anesth Analg 2005;100:5965.

23. Mannino DM, Mott J, Ferdinands JM, et al. Boys with high body masses have an increased risk of developing asthma: findings from the National Longitudinal Survey of Youth (NLSY). Int J Obes 2006;30:6-3.

24. Tait AR, Voepel-Lewis T, Buke C, et al. Incidence and risk factors for perioperative adverse respiratory events in children who are obese. Anesthesiology 2008;108: 375-80.

25. El-Metainy S, Ghoneim T, Aridae E, et al. Incidence of perioperative adverse events in obese children undergoing elective general surgery. Br J Anaesth 2011;106:35963.

26. Shore AS. Obesity and asthma: possible mechanisms. J Allergy Clin Immunol 2008; 12:1087-93.

27. Dewachter P, Mouton-Faivre C, Emala CW, et al. Bronchospasm during anesthetic induction. Anesthesiology 2011;114:120010.

28. Koop CE. Adverse anesthesia events in children exposed to environmental tobacco smoke. Anesthesiology 1998;88:1141-2.

29. Lakshmipathy R, Bokesch PM, Cowan DE. et al. Environmental tobacco smoke: a risk factor for pediatric laryngospasm. Anesth Analg 1996;82:724-7.

30. Skolnick ET, Vomvolakis MA, Buck KA. Exposure to environmental tobacco smoke and the risk of adverse respiratory events in children receiving general anesthesia. Anesthesiology 1998;88:1144-53.

31. Von Ungern-Sternberg BS, Habre W. Pediatric anesthesia - potential risks and their assessment: part II. Paed Anaesth 2007;17:311-20.

32. May HA, Smyth RL, Romer HC, et al. Effect of anaesthesia on lung function in children with asthma. Br J Anaesth 1996;77: 200-02.

33. Scalfaro P, Sly PD, Sims C, et al. Salbutamol prevents the increase of respiratory resistance caused by tracheal intubation during sevoflurane anesthesia in asthmatic children. Anesth Analg 2001;93:898-902.

34. Von Ungern-Sternberg BS, Sly PD, Loh RKS, et al. Value of eosinophil cationic protein and tryptase levels in bronchoalveolar lavage fluid for predicting lung function impairment in anaesthetised, asthmatic children. Anaesthesia 2006;61:114954.

35. Sapan N, Nacarkucuk E, Canitez Y, et al. Evaluation of the need for routine preoperative latex allergy tests in children. Pediatr Int 2002;44:157-62.

36. Porri F, Pradal M, Rud C. Is systematic preoperative screening for muscle relaxant and latex allergy advisable? Allergy 1995;50:374-7.

37. Caldwell-Andrews AA, Kain ZN, Mayes LC, et al. Motivation and maternal presence during induction of anesthesia. Anesthesiology 2005;103:478-83.

38. Kain ZN, Caldwell-Andrews AA, Mayes LC, et al. Family-centered preparation for surgery improves perioperative outcomes in children. Anesthesiology 2007;106:65-74.

39. Chorney JMC, Kain ZN. Family-centered pediatric perioperative care. Anesthesiology 2010;112:751-5.

40. Cox RG, Nemish U, Ewen A, et al. Evidence-based clinical update: does premedication with oral midazolam lead to improved behavioural outcomes in children? Can J Anest 2006;53:1213-9.

41. Kil N, Zhu JF, VanWagnen C, et al. The effects of midazolam on pediatric patients with asthma. Pediatr Dent 2003;25:137-42.

42. Barnes PJ. Asthma as an axon reflex. Lancet 1986;327:242-5.

43. Kim ES, Bishop MJ. Endotracheal intubation, but not laryingeal mask airway insertion, produces reversible bronchoconstriction. Anesthesiology 1999;90:391-4.

44. Groeben H, Silvanus MT, Beste M, et al. Combined lidocaine and salbutamol inhalation for airway anesthesia markedly protects against reflex bronchoconstriction. Chest 2000;118:509-15.

45. Leicht P, Wisborg T, ChraemmerJerrgensen B. Does intravenous lidocaine prevent laryngospasm after extubation in children? Anesth Analg 1985;64:1193-6.

46. Aouad MT, Sayyid SS, Zalaket MI, et al. Intravenous lidocaine as adjuvant to sevoflurane anesthesia for endotracheal intubation in children. Anesth Analg 2003;96:1325-7.

47. Chang H-Y S, Togias A, Brown RH. The effects of systemic lidocaine on airway tone and pulmonary function in asthmatic subjects. Anesth Analg 2007;104:1109-15.

48. Adamzik M, Groeben H, Farahani R, et al. Intravenous lidocaine after tracheal intubation mitigates bronchoconstriction in patients with asthma. Anesth Analg 2007;104:168-72.

49. Burches BR, Warner DO. Bronchospasm after intravenous lidocaine. Anesth Analg 2008;107:1260-2.

50. Ho AMH, Aun CST, Karmakar MK. The margin of safety associated with the use of cuffed paediatric tracheal tubes. Anaesthesia 2002;57:169-82.

51. Weiss M, Dullenkopf A, Gysin C, et al. Shortcomings of cuffed paediatric tracheal tubes. Br J Anaesth 2004;92:78-88.

52. Cox RG. Should cuffed endotracheal tubes be used routinely in children? C J Anesth 2005;52:669-74.

53. Weber T, Salvi N, Orliaguet G, et al. Cuffed vs non cuffed endotracheal tubes for pediatric anesthesia. Paed Anaesth 2009;19:46-54.

54. Lien CA, Koff $\mathrm{H}$, Malhotra V, et al. Emergence and extubation: a systematic approach. Anesth Analg 1997;85:1177.

55. Cox RG, Lardner DR. Supraglottic airways in children: past lessons, future directions. Can J Anesth 2009;56:636-42.

56. Politis GD, Tobin JR, Morell RC, et al. Tracheal intubation of healthy pediatric patients without muscle relaxant: a survey of technique utilization and perceptions of safety. Anesth Analg 1999;88:737-41.

57. Nauheimer D, Fink H, Fuchs-Buder TH, et al. Muscle relaxant use for tracheal intubation in pediatric anaesthesia: a survey of clinical practice in Germany. Paed Anaesth 2009;19:225-31.

58. Srivastava A, Hunter JM. Reversal of neuromuscular block. Br J Anaesth 2009;103:115-29.

59. Jooste E, Zhang Y, Emala CW. Neuromuscular blocking agents' differential bronchoconstrictive potential in guinea pig airway. Anesthesiology 2007;106:76372 .

60. Bishop MJ, 0'Donnell JT, Salemi JR. Mivacurium and bronchospasm. Anesth Analg 2003;97:484-5.

61. Caldwell JE, Lau M, Fisher DM. Atracurium versus vecuronium in asthmatic patients. A blinded, randomized comparison of adverse events. Anesthesiology 1995;83:986-91.

62. Naguib M. Sugammadex: another milestone in clinical neuromuscular pharmacology. Anesth Analg 2007;104:575-81.

63. Mirakhur RK. Sugammadex in clinical practice. Anaesthesia 2009;64:45-54.

64. Von Ungern-Sternberg BS, Saudan S, Petak F et al. Desflurane but not sevoflurane impairs airway and respiratory tissue mechanics in children with susceptible airways. Anesthesiology 2008;108:216-24.

65. Habre W, Scalfaro P, Sims C, et al. Respiratory mechanics during sevoflurane anesthesia in children with and without asthma. Anesth Analg 1999;89:1177-81.

66. Thomas OE, von Ungern-Sternberg BS, Keller K, et al. Fentanyl does not reduce the incidence of laryngospasm in children anesthetized with sevoflurane. Anesthesiology 2010;113:41-7.

67. Oberer C, von Ungern-Sternberg B, Frei JF, et al. Respiratory reflex responses of the larynx differ between sevoflurane and propofol in pediatric patients. Anesthesiology 2005;103:1142-8.

68. Brown RH, Wagner EM. Mechanism of bronchoprotection by anesthetic induction agents. Propofol versus ketamine. Anesthesiology 1999;90:822-8.

69. Brown RH, Greenberg RS, Wagner EM. 
Efficacy of propofol to prevent bronchoconstriction. Effects of preservative. Anesthesiology 2001;94:851-5.

70. Eames WO, Rooke GA, Sai-Chuen R. et al. Comparison of the effects of etomidate, propofol, and thiopental on respiratory resistance after tracheal intubation. Anesthesiology 1996;84:1307-11.

71. Gleason NR, Gallos G, Zhang Y, et al. Propofol preferentially relaxes neurokinin receptor-2-induced airway smooth muscle contraction in guinea pig trachea. Anesthesiology 2010;112:1335-44.

72. Bradley AED, Tober KES, Brown RE. Use of propofol in patients with food allergies. Anaesthesia 2008;63:433-45.

73. Hofer KN, McCarthy MW, Buck ML, et al. Possible anaphylaxis after propofol in a child with food allergy. Ann Pharmacother 2003;37:398-401.

74. Habre W, Matsumoto I, Sly PD. Propofol or halothane anaesthesia for children with asthma: effects on respiratory mechanics. Br J Anaesth 1996;77:739-43.

75. Nishiyama T, Hanaoka K. Propofol-induced bronchoconstriction: two case reports. Anesth Analg 2001;93:645-6.

76. Hepner DL. Propofol-induced bronchoconstriction: asthma or allergy? Anesth Analg 2002;94:1040-5.

77. Sato T, Matsuki A, Zsigmond EK, et al. Ketamine relaxes airway smooth muscle contracted by endothelin. Anesth Analg 1997;84:900-6.

78. Rosow CE, Moss J, Philbin DM, et al. Histamine release during morphine and fentanyl anesthesia. Anesthesiology 1982;56:93-6.

79. Han JI, Lee H, Kim CH, et al. The frequency of fentanyl-induced cough in children and its effects on tracheal intubation. $\mathrm{J}$
Clin Anesth 2010;22:3-6.

80. Sammartino M, Garra R, Sbaraglia F, et al. Remifentanil in children. Paed Anaesth 2010;20:246-55.

81. Kim JY, Park KS, Kim JS, et al. The effect of lidocaine on remifentanil-induced cough. Anaesthesia 2008;63:495-8.

82. Tweed WA, Dakin D. Explosive coughing after bolus fentanyl injection. Anesth Analg 2001;92:1442-3.

83. Oshima T, Kasuya Y, Okumura Y, et al. Identification of independent risk factors for fentanyl-induced cough. Can J Anesth 2006;53:753-8.

84. Blanch L, Bernabè F, Lucangelo U. Measurement of air trapping, intrinsic positive end expiratory pressure, and dynamic hyperinflation in mechanically ventilated patients. Respir Care 2005;50: 110-23.

85. Tuxen DV, Lane S. The effects of ventilatory pattern on hyperinflation, airway pressures, and circulation in mechanical ventilation of patients with severe airflow obstruction. Am Rev Respir Dis 1987;136: 872-9.

86. Anzueto A, Frutos-Vivar F, Esteban A, at al. Incidence, risk factors and outcome of barotrauma in mechanically ventilated patients. Intensive Care Med 2005;30:6129.

87. Marraro GA. Protective lung strategies during artificial ventilation in children. Paed Anaest 2005;15:630-7.

88. Warner D0, Warner MA, Barnes RD, et al. Perioperative respiratory complications in patients with asthma. Anesthesiology 1996;85:460-7.

89. Dewachter P, Mouton-Faivre C, Emala CW. Anaphylaxis and anesthesia. Anesthesiology 2009;111:1141-50.
90. Fisher MM, Ramakrishnan N, Doig G, et al. The investigation of bronchospasm during induction of anaesthesia. Acta Anaesthesiol Scand 2009;53:1006-11.

91. Elettrolitica equilibrata pediatrica. Diaco. Riassunto delle caratteristiche del prodotto. Available from: http:/www.diaco.it/old/ prodotti.html.

92. Sim D, Griffiths A, Armstrong D, et al Adrenal suppression from high-dose inhaled fluticasone propionate in children with asthma. Eur Respir J 2003;21:633-6.

93. Todd GRG, Acerini CL, Ross-Russell R, et al. Survey of adrenal crisis associated with inhaled corticosteroids in the United Kingdom. Arch Dis Child 2001;87:457-61.

94. Lonnqvist PA, Morton NS. Postoperative analgesia in infants and children. Br $\mathrm{J}$ Anaesth 2005;95:59-68.

95. Benini F, Barbi E, Gangemi M, et al. Il dolore nel bambino. Strumenti pratici di valutazione e terapia. Ministero della Salute. 2010. Avalaible froms: http://www. salute.gov.it/imgs/C_17_pubblicazioni_1256_allegato.pdf.

96. Eneli I, Sadri K, Camargo C, et al Acetaminophen and the risk of asthma. Chest 2005;127:604-12.

97. Lesko SM, Louik C, Vezina RM, et al. Asthma morbidity after the short-term use of ibuprofen in children. Pediatrics 2002;109. Available from: http://www.pediatrics.org/cgi/content/full/109/2/e20.

98. Boussetta K, Ponvert C, Karila C, et al. Hypersensitivity reactions to paracetamol in children: a study of 25 cases. Allergy 2005:60:1174-7.

99. Standing JF, Savage I, Pritchard D, et al. Diclofenac for acute pain in children (Cochrane review). Evid-Based Child Health 2011;6:141-206. 